\title{
(อ) OPEN ACCESS \\ Anthropometric measures that identify premature and low birth weight newborns in Ethiopia: a cross- sectional study with community follow-up
}

\author{
Netsanet Workneh Gidi 다, ${ }^{1}$ Melkamu Berhane, ${ }^{1}$ Tsinuel Girma, ${ }^{1}$ Alemseged Abdissa, ${ }^{2}$ \\ Ruth Lim, ${ }^{3}$ Katherine Lee, ${ }^{3,4}$ Cattram Nguyen, ${ }^{3,4}$ Fiona Russell $\|^{3,4}$
}

Department of Pediatrics and Child Health, Jimma University, Jimma, Ethiopia

Department of Medical Laboratory Sciences and Pathology, Jimma University, Jimma, Ethiopia

${ }^{3}$ Murdoch Children's Research Institute, The Royal Children's Hospital, Melbourne, Victoria, Australia

${ }^{4}$ Department of Pediatrics, The University of Melbourne, Melbourne, Victoria, Australia

\section{Correspondence to}

Dr Netsanet Workneh Gidi, Department of Pediatrics and Child Health, Jimma University, Jimma, Ethiopia;

konetsanet@gmail.com

Received 28 April 2019 Revised 29 August 2019 Accepted 1 October 2019 Published Online First

1 November 2019

Check for updates

(C) Author(s) (or their employer(s)) 2020. Re-use permitted under CC BY-NC. No commercial re-use. See rights and permissions. Published by BMJ.

To cite: Gidi NW, Berhane $M$ Girma T, et al. Arch Dis Child 2020:105:326-331.

\section{ABSTRACT}

Objective To investigate foot length (FL), chest circumference (CHC) and mid-upper arm circumference (MUAC) as predictors of low birth weight (LBW) or prematurity, and to describe the agreement between the gestational age (GA) assessments ascertained by the New Ballard Score (NBS) and the Eregie model.

Methods A hospital-based cross-sectional study with community follow-up in a subset was conducted in Jimma University Medical Center, Ethiopia. GA (NBS and Eregie model), weight, FL, CHC and MUAC were measured at birth. Anthropometrics were repeated at 5 days of age.

Results The optimal cut-offs indicative of LBW were $\leq 7.7 \mathrm{~cm}$ for $\mathrm{FL} ; \leq 31.2 \mathrm{~cm}$ for $\mathrm{CHC}$ and $\leq 9.8 \mathrm{~cm}$ for MUAC. CHC, MUAC and FL identified LBW with sensitivities ( $95 \% \mathrm{Cl}$ ) of 91.6 (86.9 to 95$), 83.7$ (77.8 to $88.5)$ and 84.2 (78.4 to 88.9$)$, and specificities $(95 \% \mathrm{Cl})$ of 85.4 (83.3 to 87.4), 90.2 (88.4 to 91.9) and 73.9 (71.3 to 76.4), respectively. CHC, MUAC and FL identified prematurity with sensitivities of 83.8 (76.7 to 89.4), 83.1 (75.9 to 88.9) and 81.7 (74.3 to 87.7), and specificities of 81.1 (78.9 to 83.3), 63.4 (60.7 to 66.1) and 77.0 (74.6 to 79.3), respectively. The cut-offs identified have comparable diagnostic ability for LBW and prematurity when measurements are repeated on day 5 of age. The GA assessment by the NBS and the Eregie model gave similar results, with the mean difference of 1.2 weeks. Conclusion CHC, MUAC and FL taken on day 1 and 5 after birth could be used as diagnostic tools for LBW or prematurity. The Eregie model for GA estimation gives similar results to the NBS.

\section{INTRODUCTION}

Child mortality has declined dramatically in the 20th century worldwide. ${ }^{1}$ However, the reduction in neonatal mortality has been slow, and neonatal deaths still contribute almost half $(41.6 \%)$ of all under-5 mortality. ${ }^{2}$ About one-sixth of all newborns are low birth weight (LBW, $<2500 \mathrm{~g}$ ), which is the single most important underlying risk factor for neonatal death. ${ }^{3}$ Ethiopia has one of the highest neonatal mortality rates in the world (29 per 1000 live births). ${ }^{4}$ Similar to other sub-Saharan countries, the proportion of births attended by skilled health personnel is low, so most LBW and preterm newborns are unlikely to be identified and referred for additional lifesaving care. ${ }^{45}$ Moreover, access to weighing scales is limited in many community settings. Therefore, simple, low-cost instruments

\section{What is already known on this topic?}

- Worldwide, about one-sixth of all newborns are low birth weight (LBW, $<2500 \mathrm{~g}$ ), which is the single most important underlying risk factor for neonatal death.

- In resource-limited settings, tools to identify LBW and premature newborns are often not readily available.

- Foot length, chest circumference mid-upper arm circumference can be used to identify LBW babies at birth, cut-offs vary by country and ethnic group.

\section{What this study adds?}

- The optimal cut-offs identified to diagnose LBW in Ethiopia were $\leq 7.7 \mathrm{~cm}$ for foot length, $\leq 31.2 \mathrm{~cm}$ for chest circumference and $\leq 9.8 \mathrm{~cm}$ for mid-upper arm circumference.

- Comparable diagnostic ability was observed when these measurements were taken on day 5 of age.

- The Eregie model for gestational age estimation gives similar results to the New Ballard Score method.

that are suitable for resource-limited settings are urgently required, to ensure these vulnerable infants are identified and referred as required for additional care. Simple and reliable anthropometric tools to identify LBW and preterm babies have been proposed by several authors with various cut-off values. ${ }^{6-16}$ A multicentre study carried out by WHO found that the mean and 10th percentile for the mid-upper arm circumference (MUAC) and chest circumference $(\mathrm{CHC})$ varied by country and ethnic group. Hence, there is a need to identify a suitable anthropometric surrogate and define its cut-off for identifying LBW and prematurity in different populations. $^{15}$

The determination of gestational age (GA) is most accurate if determined by ultrasound examination in early pregnancy or the date of the last menstrual period. ${ }^{17}$ However, in a setting where antenatal care is inadequate, this information is not readily available. Several authors have reported different methods for estimating GA based on 


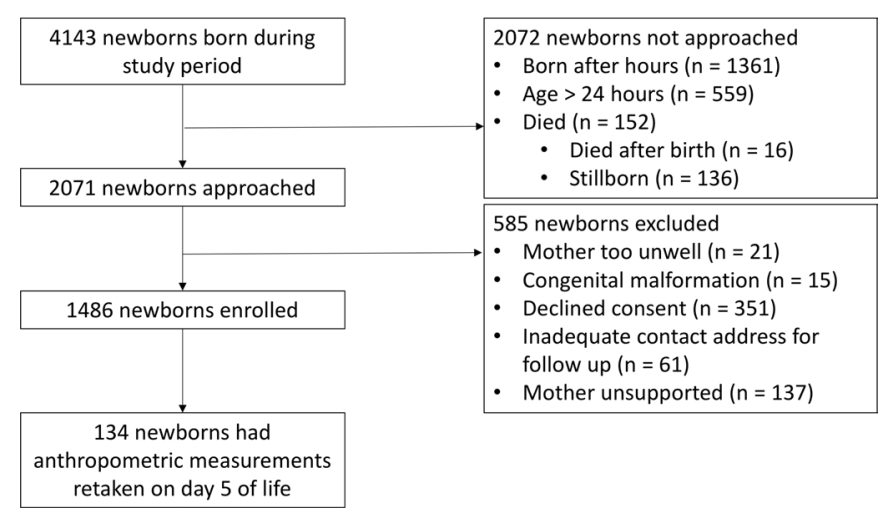

Figure 1 Flow chart of recruitment of study participants at Jimma University Medical Center, Ethiopia ( $n=1486)$.

neuromuscular and physical maturity rating. The New Ballard score (NBS) has been widely used clinically in resource-limited settings and may be considered as the gold standard. ${ }^{19}$ An alternative measurement, the Eregie model, which has been adapted from the Dubowitz GA assessment, has been evaluated as an appropriate clinical tool for rapid and reliable maturity determination in healthy and sick African newborns. ${ }^{20}$ However, there are few studies assessing the accuracy of the Eregie model in determining GA.

\section{OBJECTIVES}

The aims of this study were (1) to describe the diagnostic value of FL, CHC and MUAC taken within 24 hours of birth to identify LBW and preterm newborns in Ethiopia; (2) to compare the cut-offs identified for diagnosis based on 24 hours measurement for CHC, MUAC and FL, in detecting LBW or prematurity within the first 24 hours and on day 5 of life and (3) to describe the agreement between the GA assessment ascertained by the NBS and the Eregie model.

\section{METHODS}

\section{Study setting and design}

This was a hospital-based cross-sectional study with community follow-up in a subset of neonates. The study was undertaken in Jimma University Medical Center, Jimma Town, south-west Ethiopia, the only referral tertiary hospital for this area, which serves a population of 15 million people. Many of the Jimma University Medical Center patients are referred from surrounding rural health centres and regional hospitals. There are approximately 6000 live births each year at the Medical Center.

\section{Study participants}

Live-born newborns between December 2014 and November 2016, and whose parents gave informed consent and complete address including phone number, were enrolled in the study (the latter was required for the 5-day follow-up). Newborns that were older than 24 hours and those with major/gross congenital anomalies and dysmorphic features were excluded, as these conditions may affect anthropometric measurements. In addition, mothers who were deemed too unwell were excluded from the study. On day 5 of life, anthropometric measurements were repeated for participants who returned for follow-up.

\section{Study procedures}

The study was carried out according to Good Clinical Practice. ${ }^{21}$ Standard operating procedures were developed for all study procedures. Recruitment occurred between Monday and Friday each week. The purpose of the study was explained to the parent/guardian in the parent's/guardian's native language and witnessed, written informed consent was obtained. For those parents/guardians who were illiterate, a witnessed thumb stamp was obtained. Two on-site paediatricians (NWG, MB) were trained by the principal investigator paediatrician (FR) on how to measure the newborns' FL, CHC and MUAC. GA was clinically assessed using the NBS and Eregie model. ${ }^{22-24}$ Based on the parameters of Eregie model, six physical characteristics of newborns were examined and scored for signs of maturity (skin, eyes/ears, breast size, genitalia, MUAC and head circumference). As no postnatal assessment of GA has been validated in Ethiopia, the most uniformly used gestational assessment tool, the NBS, was also undertaken as the gold standard. The NBS uses 13 physical and neurological signs to assess maturity. Prematurity was defined as gestational age $<37$ weeks.

Birth weight was measured with a calibrated digital weighing scale (Salter digital toddler/baby scale, model WS034, UK) to the nearest $10 \mathrm{~g}$. FL was taken to the nearest $0.1 \mathrm{~cm}$ using a stiff transparent plastic metric ruler; other anthropometric variables were also measured to the nearest $0.1 \mathrm{~cm}$ using a non-elastic, flexible measuring tape. MUAC was measured at the mid-point between the tip of acromion process and olecranon process of the right upper arm. FL was measured from the centre of the heel pad to the middle of the tip of hallux toe on the right foot. $\mathrm{CHC}$ was measured at the level of the nipple during expiration. All measurements were done in triplicate; the mean of the measurements was used for analyses. On day 5 of life, $\mathrm{CHC}$, MUAC and FL were measured again on participants who could be located in the community for follow-up. The repeat measurements were considered as in Ethiopia many newborns are born in the community and may not see a community health worker until up to a few days following delivery. We wanted to ensure that results were also valid for this common scenario.

All data were collected on study-specific forms. Data collection forms were checked for logical errors and completeness prior to data entry. Data were doubly entered into EpiData V.3.1 and analysed using Stata V.14.1.

\section{Data analysis}

Continuous variables were presented as means and SDs (or medians and IQRs if not normally distributed), and categorical variables as the number and proportion in each category. Receiver operating characteristic curves were generated to identify the optimal cut-point for each of the anthropometric indicators taken within 24 hours for identifying LBW or prematurity (based on the NBS and the Eregie model) with $\geq 80 \%$ sensitivity. The sensitivity, specificity and positive and negative predictive values for each of the optimal cut-points applied to the data within 24 hours were calculated. The difference in CHC, MUAC and FL taken within the first 24 hours and on day 5 of life was assessed using a paired t-test, with a separate analysis for each measurement. Results are presented as a mean difference, 95\% $\mathrm{CI}$ and a $\mathrm{p}$ value. Finally, we assessed the agreement in the GA estimates ascertained by the NBS and the Eregie model using a Bland-Altman plot of agreement.

\section{Sample size}

The required sample size $(n=1486)$ was determined based on the number of newborns necessary to estimate the sensitivity of an anthropometric measurement as a predictor for mortality, the original aim of the study. Assuming 90\% sensitivity, the 
Table 1 Demographic and clinical characteristics of the study participants at Jimma University Medical Center, Ethiopia $(n=1486$ )

\begin{tabular}{lc}
\hline Variable & Summary statistic \\
\hline Sex, $\mathrm{n}(\%)$ & \\
\hline Male & $818(55.0)$ \\
\hline Ethnicity, $\mathrm{n}(\%)$ & $1054(70.9)$ \\
\hline Oromo & $128(8.6)$ \\
\hline Amhara & $84(5.7)$ \\
\hline Yem & $60(4.0)$ \\
\hline Kaffa & $57(3.8)$ \\
\hline Dawro & $13(0.9)$ \\
\hline Tigry & $90(6.1)$ \\
\hline Other & \\
\hline Mother's schooling, $\mathrm{n}$ (\%) & $338(22.7)$ \\
\hline Illiterate & $520(35.0)$ \\
\hline Primary & $358(24.1)$ \\
\hline Secondary & $270(18.2)$ \\
\hline Technical/vocational and higher & $25.0(5.0)$ \\
\hline Mother's age in years, mean (SD) & $2974(494)$ \\
\hline Birth weight (g), mean (SD) & $203(14.6)$ \\
\hline Low birth weight, $\mathrm{n}$ (\%) & $32.7(2.3)$ \\
\hline Chest circumference in cm—day 1, mean (SD) & $33.5(2.5)$ \\
\hline Chest circumference in cm—day 5, mean (SD) & $10.4(1.0)$ \\
\hline MUAC in cm—day 1, mean (SD) & $10.0(1.0)$ \\
\hline MUAC in cm—day 5, mean (SD) & $7.8(0.5)$ \\
\hline Foot length in cm—day 1, mean (SD) & $7.9(0.5)$ \\
\hline Foot length in cm—day 5, mean (SD) & $39.0(38.0-40.0)$ \\
\hline GA by New Ballard Score, median (IQR) & $40.0(40.0-41.0)$ \\
\hline GA by Eregie model, median (IQR) & $143(10.2)$ \\
\hline Premature by New Ballard Score, $\mathrm{n}(\%)$ & $77(5.5)$ \\
\hline Premature by Eregie model, $\mathrm{n}(\%)$ & \\
\hline & \\
\hline
\end{tabular}

Prematurity, defined as $\mathrm{GA}<37$ weeks. Due to missing data, $\mathrm{n}$ ranged between 1390 and 1486 for day 1 variables, and between 132 and 136 for day 5 variables. $\mathrm{GA}$, gestational age; MUAC, mid-upper arm circumference.

minimum sensitivity thought to be acceptable for a diagnostic tool in this context, 55 deaths would be required to estimate the
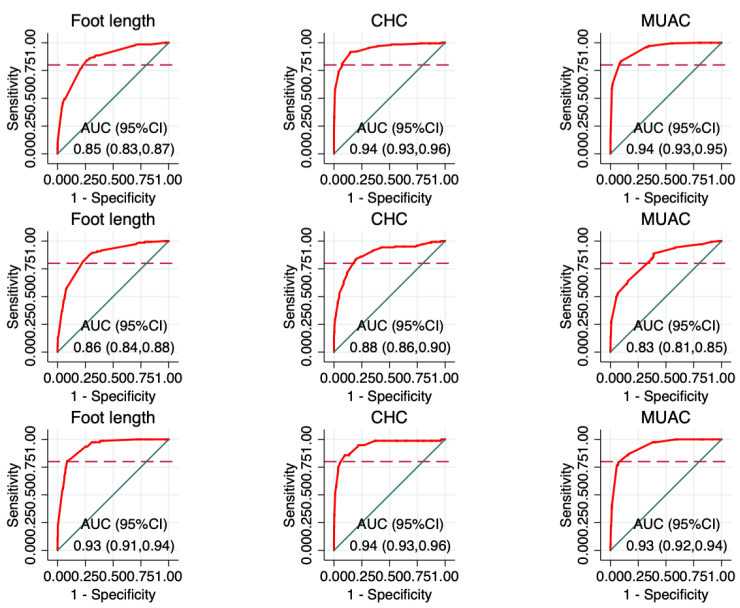

Figure 2 Receiver operating characteristic curves for anthropometric measures as diagnostic tools of low birth weight (top row), prematurity ( $<37$ weeks) using the New Ballard Score (middle row) and prematurity ( $<37$ weeks) using the Eregie model (bottom row). AUC, area under the curve; $\mathrm{CHC}$, chest circumference; MUAC, mid-upperarm circumference. sensitivity within $8 \%$ (based on a $95 \% \mathrm{CI}$ ). Assuming a neonatal mortality rate of 37 per 1000 live births, obtaining 55 deaths requires a sample size of 1486 newborns. However, as the study progressed there were much fewer deaths than expected (12 deaths), hence we were not sufficiently powered to answer our original primary aim as intended. This could have been due to the inclusion criteria, as only newborns presenting $<24$ hours of age were considered eligible and many newborns who died were referred or presented after 24 hours of age. In this manuscript, we consider the more prevalent outcomes, prematurity and LBW where there is greater statistical power.

\section{RESULTS}

A total of 4143 newborns were born during the study period in Jimma University Medical Center, of whom 136 were stillbirth and 16 died immediately after birth. Half of the parents of live-born infants were invited into the study $(n=2071)$ and 1486 newborns were recruited. Day 5 follow-up examination was conducted on 134 participants (figure 1).

Table 1 shows the demographic characteristics of the mothers and their newborns. The mean age of the mothers was 25 years, and the majority $(70.9 \%)$ were from the Oromo ethnic group. The mean birth weight of the newborns was $2974 \mathrm{~g}(\mathrm{SD}=494$ g), with $14.6 \%$ being LBW and 55\% were male. The median GA by NBS was 39 weeks (IQR 38-40 weeks), while it was 40 weeks (IQR 40-41 weeks) by the Ergie model.

$\mathrm{CHC}$ and MUAC were found to be the best anthropometric diagnostic measure of LBW with the highest area under the receiver operating characteristic curve (AUC) $(0.94) \quad(95 \% \mathrm{CI}$ 0.93 to 0.96 ) and 0.94 (95\% CI 0.93 to 0.95$)$, respectively, with a slightly lower AUC for FL, 0.85 (95\% CI 0.83 to 0.87). Using FL, $\mathrm{CHC}$ and MUAC as a diagnostic tool for prematurity estimated using the NBS gave an AUC of 0.86 (95\% CI 0.84 to 0.88 ), 0.88 (95\% CI 0.86 to 0.9 ), 0.83 (95\% CI 0.81 to 0.85 ), respectively. Prediction of prematurity estimated using the Eregie model had higher AUCs in all the measurements, AUC of 0.93 (95\% CI 0.91 to 0.94 ), 0.94 (95\% CI 0.93 to 0.96 ), 0.93 (95\% CI 0.92 to 0.94 ) for FL; CHC and MUAC, respectively (figure 2).

The optimal cut-points of anthropometric indicators taken within 24 hours of life chosen to have $\geq 80 \%$ sensitivity in predicting LBW and preterm newborns were $7.4-7.7 \mathrm{~cm}$ for FL, $30.1-31.4 \mathrm{~cm}$ for CHC and $9.5-10 \mathrm{~cm}$ for MUAC (table 2).

MUAC had the highest specificity (90.2\%), CHC had the highest sensitivity (91.6\%) and FL had the lowest specificity (73.9\%) for detecting LBW (table 2). Both MUAC and CHC had equally optimal sensitivity for detecting prematurity estimated via the Eregie model (85.7\%), with slightly higher specificity with the FL. Applying these cut-points to the measurements taken on day 5, MUAC had the highest sensitivity for detecting LBW (95.2\%), while the specificity was lower than that of $\mathrm{CHC}$ and FL (70.6\%), whereas CHC had the highest specificity (93.1\%) (table 3).

On average, FL and $\mathrm{CHC}$ were slightly larger on day 5 compared with within 24 hours of life, and MUAC was slightly smaller (table 4). Figure 3 shows a Bland-Altman plot of agreement between the GA assessments determined by the NBS and the Eregie model. The two tools gave similar results, with the NBS estimates of GA being 1.2 weeks lower than the Eregie model estimates on average $(95 \%$ limits of agreement -4.0 to $1.5)$.

\section{DISCUSSION}

In our study, we found that all three anthropometric parameters (FL, MUAC and CHC) appeared to be useful diagnostic tools 
Table 2 Sensitivity, specificity, positive predictive values (PPV) and negative predictive values (NPV) with 95\% Cls for each outcome and anthropometric measured within 24 hours of life $(n=1389)$

\begin{tabular}{|c|c|c|c|c|}
\hline Outcome & $\begin{array}{l}\text { Sensitivity } \\
(95 \% \mathrm{CI})\end{array}$ & $\begin{array}{l}\text { Specificity } \\
(95 \% \mathrm{Cl})\end{array}$ & $\begin{array}{l}\text { PPV } \\
(95 \% \mathrm{Cl})\end{array}$ & $\begin{array}{l}\text { NPV } \\
(95 \% \mathrm{CI})\end{array}$ \\
\hline \multicolumn{5}{|c|}{ Low birth weight $(<2500 \mathrm{~g})$} \\
\hline $\mathrm{FL} \leq 7.7 \mathrm{~cm}$ & 84.2 (78.4 to 88.9$)$ & 73.9 (71.3 to 76.4$)$ & 35.4 (31.1 to 39.9$)$ & 96.5 (95.1 to 97.6$)$ \\
\hline $\mathrm{CHC} \leq 31.2 \mathrm{~cm}$ & 91.6 (86.9 to 95.0$)$ & 85.4 (83.3 to 87.4$)$ & 51.7 (46.4 to 57.0$)$ & $98.4(97.4$ to 99.0$)$ \\
\hline $\mathrm{MUAC} \leq 9.8 \mathrm{~cm}$ & 83.7 (77.8 to 88.5$)$ & 90.2 (88.4 to 91.9$)$ & 59.3 (53.3 to 65.1) & 97.0 (95.8 to 97.9$)$ \\
\hline \multicolumn{5}{|c|}{ Premature-New Ballard Score } \\
\hline $\mathrm{FL} \leq 7.5 \mathrm{~cm}$ & 81.7 (74.3 to 87.7$)$ & 77.0 (74.6 to 79.3$)$ & 28.6 (24.3 to 33.3) & 97.4 (96.2 to 98.3$)$ \\
\hline $\mathrm{CHC} \leq 31.4 \mathrm{~cm}$ & 83.8 (76.7 to 89.4$)$ & 80.2 (77.9 to 82.3$)$ & 32.3 (27.6 to 37.4$)$ & 97.8 (96.7 to 98.6$)$ \\
\hline$M U A C \leq 10.0 \mathrm{~cm}$ & 83.1 (75.9 to 88.9$)$ & $63.4(60.7$ to 66.1$)$ & 20.4 (17.2 to 23.9$)$ & 97.1 (95.7 to 98.1$)$ \\
\hline \multicolumn{5}{|c|}{ Premature-Eregie model } \\
\hline $\mathrm{FL} \leq 7.4 \mathrm{~cm}$ & 80.5 (69.9 to 88.7$)$ & 91.4 (89.7 to 92.8$)$ & 35.2 (28.2 to 42.8$)$ & 98.8 (98.0 to 99.3$)$ \\
\hline $\mathrm{CHC} \leq 30.1 \mathrm{~cm}$ & 85.7 (75.9 to 92.6$)$ & 90.2 (88.5 to 91.8$)$ & $33.8(27.2$ to 41.0$)$ & 99.1 (98.4 to 99.5) \\
\hline$M U A C \leq 9.5 \mathrm{~cm}$ & 85.7 (75.9 to 92.6$)$ & 84.9 (82.8 to 86.8$)$ & 24.8 (19.7 to 30.5$)$ & 99.0 (98.3 to 99.5$)$ \\
\hline
\end{tabular}

CHC, chest circumference; FL, foot length; MUAC, mid-upper arm circumference.

for LBW or prematurity. However, similar to the findings of the WHO collaborative study and a meta-analysis, we found $\mathrm{CHC}$ and MUAC to have better predictive ability than FL. ${ }^{1525}$ The cutoffs identified for LBW and preterm newborns using CHC in this study were between 30.1 and $31.4 \mathrm{~cm}$, which is similar to studies from Nepal, Uganda, Vietnam and Mekelle, Ethiopia, which were $30.8 \mathrm{~cm}, 31 \mathrm{~cm}$, between 30 and $30.4 \mathrm{~cm}$ and $30.15 \mathrm{~cm}$, respectively, ${ }^{142627}$ and higher than the cut-offs suggested by WHO collaborative study (with interpretation of $<29 \mathrm{~cm}$ 'highly at risk' and between 29 and 30 as 'at risk'). ${ }^{15}$ The cut-offs we identified using the MUAC were between 9.5 and $10 \mathrm{~cm}$, similar to the findings from the WHO collaborative study, but slightly higher than that of study from Vietnam which reported 8.7 and $9.0 \mathrm{~cm}$ and from Turkey which reported $9 \mathrm{~cm}^{151626}$ The cut-off point for FL identified in the current study was between 7.4 and $7.7 \mathrm{~cm}$, which is similar to the finding from Mekelle, Ethiopia $(7.5 \mathrm{~cm})$ and slightly lower than Ugandan and Tanzanian studies, which were 7.9 and $8 \mathrm{~cm}$, respectively. ${ }^{10} 1416$

The use of $\mathrm{CHC}$ as a surrogate for identifying LBW infants has been recommended in several studies, mainly due to its high sensitivity to diagnose LBW and the simplicity of the procedure as the nipple line makes an obvious landmark for measurement so is less prone to interobserver or intraobserver variability. Similarly, our findings show $\mathrm{CHC}$ having the best diagnostic ability for LBW and prematurity, with AUCs of 0.94, 0.88 and 0.94 for LBW, and prematurity assessed using NBS and Eregie model, respectively. Using a cut-off of $<31.2 \mathrm{~cm}$ for CHC measured within 24 hours of life identified $91.6 \%$ of LBW babies and cut-off of $<31.4 \mathrm{~cm}$ identified $83.8 \%$ premature babies, which is like the pooled sensitivity of CHC (88\%) in detecting LBW babies reported in a meta-analysis, and the specificity we observed is comparable to the meta-analysis findings (90\%). ${ }^{16}$ The MUAC also appears to have high sensitivity in identifying LBW and correctly identified $83.7 \%$ of LBW babies when measured on the first day of life and $95.2 \%$ when measured on day 5. Of note, the best diagnostic tool for prematurity appears to be MUAC on day 5, with $100 \%$ sensitivity, on both methods of GA assessment used. However, this was only assessed in the subgroup with data at day 5 and the procedure of measuring MUAC is more likely to be associated with higher interobserver variability than FL or $\mathrm{CHC}$ as identifying a landmark to measure is not easy compared with the other measurements. ${ }^{152526} \mathrm{FL}<7.7 \mathrm{~cm}$ taken at birth was found to be $84.2 \%$ sensitive and $73.9 \%$ specific in diagnosing LBW newborns, which is like the findings from Ugandan and north Ethiopian study with sensitivity and specificity of $85 \%$ and $81 \% ; 78.9 \%$ and $86.7 \%$, respectively. The sensitivity of $\mathrm{CHC}(91.6 \%)$ in detecting LBW was better than FL and MUAC, with the highest negative predictive value (NPV) (98.4\%) and the positive predictive value (PPV) was

Table 3 Sensitivity, specificity, positive predictive values (PPV) and negative predictive values (NPV) with 95\% Cls for each outcome and anthropometric measured on day 5 of life, using the cut-offs identified based on measurements taken within 24 hours of life ( $n=123$ )

\begin{tabular}{|c|c|c|c|c|}
\hline Outcome & $\begin{array}{l}\text { Sensitivity } \\
(95 \% \mathrm{CI})\end{array}$ & $\begin{array}{l}\text { Specificity } \\
(95 \% \mathrm{CI})\end{array}$ & $\begin{array}{l}\text { PPV } \\
(95 \% \mathrm{Cl})\end{array}$ & $\begin{array}{l}\text { NPV } \\
(95 \% \mathrm{Cl})\end{array}$ \\
\hline \multicolumn{5}{|c|}{ Low birth weight $(<2500 \mathrm{~g})$} \\
\hline $\mathrm{FL} \leq 7.7 \mathrm{~cm}$ & 71.4 (47.8 to 88.7$)$ & 75.5 (66.0 to 83.5$)$ & 37.5 (22.7 to 54.2$)$ & 92.8 (84.9 to 97.3$)$ \\
\hline $\mathrm{CHC} \leq 31.2 \mathrm{~cm}$ & 71.4 (47.8 to 88.7$)$ & 93.1 (86.4 to 97.2 ) & 68.2 (45.1 to 86.1 ) & 94.1 (87.5 to 97.8 ) \\
\hline$M U A C \leq 9.8 \mathrm{~cm}$ & 95.2 (76.2 to 99.9$)$ & 70.6 (60.7 to 79.2$)$ & 40.0 (26.4 to 54.8$)$ & 98.6 (92.6 to 100$)$ \\
\hline \multicolumn{5}{|c|}{ Premature-New Ballard Score } \\
\hline $\mathrm{FL} \leq 7.5 \mathrm{~cm}$ & $60.0(26.2$ to 87.8$)$ & 78.8 (70.3 to 85.8$)$ & $19.4(7.5$ to 37.5$)$ & 95.9 (89.8 to 98.9$)$ \\
\hline $\mathrm{CHC} \leq 31.4 \mathrm{~cm}$ & $60.0(26.2$ to 87.8$)$ & 84.7 (77.0 to 90.7$)$ & $25.0(9.8$ to 46.7$)$ & 96.2 (90.4 to 98.9$)$ \\
\hline$M U A C \leq 10 \mathrm{~cm}$ & $100(69.2$ to 100$)$ & 46.6 (37.4 to 56.0$)$ & $13.7(6.8$ to 23.8$)$ & 100 (93.5 to 100$)$ \\
\hline \multicolumn{5}{|c|}{ Premature-Eregie model } \\
\hline $\mathrm{FL} \leq 7.4 \mathrm{~cm}$ & 62.5 (24.5 to 91.5$)$ & 93.3 (87.3 to 97.1$)$ & 38.5 (13.9 to 68.4$)$ & 97.4 (92.6 to 99.5$)$ \\
\hline $\mathrm{CHC} \leq 30.1 \mathrm{~cm}$ & 75.0 (34.9 to 96.8$)$ & 93.3 (87.3 to 97.1$)$ & 42.9 (17.7 to 71.1$)$ & 98.2 (93.8 to 99.8$)$ \\
\hline$M U A C \leq 9.5 \mathrm{~cm}$ & $100(63.1$ to 100$)$ & 67.5 (58.3 to 75.8$)$ & $17.0(7.6$ to 30.8$)$ & 100 (95.5 to 100$)$ \\
\hline
\end{tabular}

CHC, chest circumference; FL, foot length; MUAC, mid-upper arm circumference. 
Table 4 Comparison of anthropometric measures taken within 24 hours of life and day 5 of life $(n=127)$

\begin{tabular}{|c|c|c|c|c|c|c|c|}
\hline \multirow[b]{2}{*}{$\mathrm{FL}$} & \multicolumn{2}{|c|}{ Mean (SD) at day 1 of life } & \multicolumn{2}{|c|}{ Mean (SD) at day 5 of life } & \multirow{2}{*}{$\begin{array}{l}\begin{array}{l}\text { Mean difference } \\
\text { (day 1-day 5) }\end{array} \\
-0.09\end{array}$} & \multirow{2}{*}{$\frac{95 \% \mathrm{Cl}}{-0.14 \text { to }-0.03}$} & \multirow{2}{*}{$\frac{P \text { value }}{0.003}$} \\
\hline & 7.82 & $(0.49)$ & 7.91 & $(0.49)$ & & & \\
\hline MUAC & 10.27 & $(0.89)$ & 9.98 & $(1.04)$ & 0.29 & 0.17 to 0.40 & $<0.001$ \\
\hline $\mathrm{CHC}$ & 33.02 & (2.44) & 33.42 & (2.40) & -0.40 & -0.66 to -0.13 & 0.004 \\
\hline
\end{tabular}

CHC, chest circumference; $\mathrm{FL}$, foot length; MUAC, mid-upper arm circumference.

51.7\%, higher than the report from Bangladesh (8\%-19\%), and lower than the finding of north Ethiopian study, which reported PPV of $72 \%$; the lower PPV can be explained by the lower prevalence. While the NPV observed in this study was comparable with the other measurements 96\%-97\% and the finding of north Ethiopian study (PPV of 91\%). ${ }^{10} 2728$

Comparison of the measurements taken within 24 hours of life and on day 5 found that on average FL and CHC were slightly larger on day 5 but MUAC was a little smaller. The cut-offs identified within 24 hours has detected LBW and prematurity on day 5 , with slight difference in the sensitivity and specificity of the measurements in detecting both LBW or prematurity compared with the measurements within 24 hours.

GA estimation based on ultrasound examination in early pregnancy and the date of the last menstrual period is highly accurate, with systematic errors of less than $<1$ week compared with postnatal estimates. ${ }^{17}$ However, where this information is not available, clinicians often use newborn GA assessments using the Dubowitz or Ballard examinations, which are standardised scoring systems based on the physical and neuromuscular maturity of the infant. These methods of GA estimation are the only currently available options in resource-limited settings with inadequate antenatal care. Newborn estimates tend to overestimate the gestation of infants born at $<40$ weeks, while underestimating the gestation of infants born at $\geq 40$ weeks. $^{20}$ As reported by Marin Gabriel et al, differences of $>2$ weeks in GA were seen frequently when the agreement of GA assessment by NBS was compared with last menstrual period/ ultrasound methods. ${ }^{19}$ The Eregie model adapted the Dubowitz score for African newborns, using six parameters, reported to be accurate for rapid clinical assessment. ${ }^{29}$ In our study, the NBS was 1.2 points lower than the Eregie scores, on average. Based on the

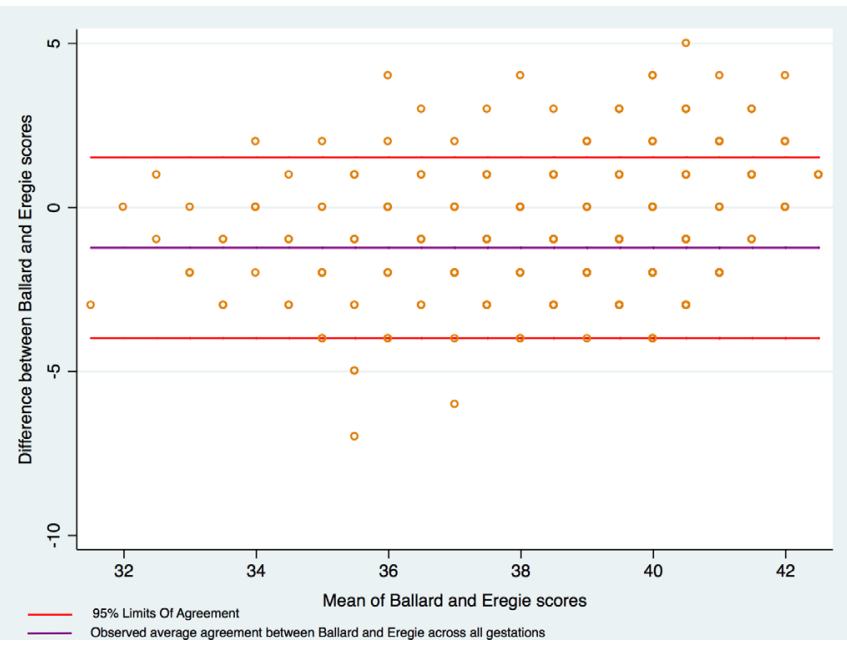

Figure 3 Bland-Altman plot of agreement between the New Ballard Score and the Eregie model for estimating gestational age. Average difference (New Ballard Score minus Eregie model) $=-1.2,95 \%$ limits of agreement $=-4.0$ to 1.5 .
95\% limits of agreement, we would expect the majority of differences between the NBS and Eregie estimates to range between -4 and 1.5. The points on the Bland-Altman plot take on the shape of horizontal band, suggesting that the differences between the NBS and Eregie scores do not systematically differ across the range of GA. As the Eregie model uses fewer parameters for quick evaluation, we propose that until better diagnostics for GA are identified, the Eregie model could be used as an alternative to the NBS in resource-limited settings. However, further validation in other settings is required.

A limitation of this study is the method we used to estimate GA. Prematurity is best assessed by early ultrasound examination, however, in this study NBS and Eregie model were used, as majority of the mothers do not remember their last menstrual period and antenatal ultrasound is not routinely performed at heath facilities in Ethiopia, which may introduce an error in estimation of GA.

\section{CONCLUSION}

All the three newborn measurements studied (FL, MUAC and CHC) could be used as a diagnostic tool to identify LBW and preterm newborns needing extra care when taken at birth and up to day 5 of life. In this study, CHC and FL appear to be the best anthropometric measurements identified. CHC is the most appropriate diagnostic measure of LBW and prematurity due to its operational feasibility given the simplicity of the procedure. However, measurement of MUAC on day 5 potentially had better sensitivity for identifying LBW newborns and prematurity than the other parameters studied. The Eregie model for GA estimation gives similar results to the NBS method. Further research is required to identify better diagnostic measures of LBW or prematurity in lowresource settings.

\section{Twitter Netsanet Workneh Gidi @netsanetw}

Acknowledgements The authors would like to thank International Pediatric Association and Murdoch Children's Research Institute for funding this research. The authors would also like to thank all families who participated in this study.

Contributors FR, TG and AA conceptualised and designed the study. NWG coordinated and supervised data collection and drafted the initial manuscript. MB collected the data. $\mathrm{KL}$ and $\mathrm{CN}$ contributed to the design and statistical analysis. $\mathrm{RL}$ reviewed the data collection and study procedures. All authors revised the work critically and approved the final manuscript as submitted and agreed to be accountable for all aspects of the work.

Funding International Pediatric Association and Murdoch Children's Research Institute Theme grant; FR was supported by a NHMRC Early Career Fellowship and NHMRC TRIP Fellowship.

Competing interests None declared.

\section{Patient consent for publication Not required.}

Ethics approval This study was performed according to the protocol approved by the Jimma University Ethics Review Committee and The University of Melbourne Human Research Ethics Committee (Ethics ID: 1442168).

Provenance and peer review Not commissioned; externally peer reviewed. Data availability statement Data are available on reasonable request.

Open access This is an open access article distributed in accordance with the Creative Commons Attribution Non Commercial (CC BY-NC 4.0) license, which 
permits others to distribute, remix, adapt, build upon this work non-commercially, and license their derivative works on different terms, provided the original work is properly cited, appropriate credit is given, any changes made indicated, and the use is non-commercial. See: http://creativecommons.org/licenses/by-nc/4.0/.

\section{ORCID iD}

Netsanet Workneh Gidi http://orcid.org/0000-0002-7213-8178

\section{REFERENCES}

1 Ahmad OB, Lopez AD, Inoue M. The decline in child mortality: a reappraisal. Bull World Health Organ 2000;78:1175-91.

2 Wang $\mathrm{H}$, Liddell CA, Coates MM, et al. Global, regional, and national levels of neonatal, infant, and under-5 mortality during 1990-2013: a systematic analysis for the global burden of disease study 2013. Lancet 2014;384:957-79.

3 Black RE, Levin C, Walker N, et al. Reproductive, maternal, newborn, and child health: key messages from disease control priorities 3rd edition. Lancet 2016;388:2811-24.

4 Ethiopia Demographic and Health Survey. 2016: Key Indicators Report. Central Statistical Agency (CSA) [Ethiopia] and ICF: Addis Ababa, Ethiopia, and Rockville, Maryland, USA. CSA and ICF, 2016.

5 Friberg IK, Kinney MV, Lawn JE, et al. Sub-Saharan Africa's mothers, newborns, and children: how many lives could be saved with targeted health interventions? PLOS Med 2010;7:e1000295.

6 Daga SR, Daga AS, Patole $S$, et al. Foot length measurement from foot print for identifying a newborn at risk. J Trop Pediatr 1988;34:16-19.

7 Hirve SS, Ganatra BR. Foot tape measure for identification of low birth weight newborns. Indian Pediatr 1993;30:25-9.

8 Ho T-Y, Ou S-F, Huang S-H, et al. Assessment of growth from foot length in Taiwanese neonates. Pediatr Neonatol 2009;50:287-90.

9 James DK, Dryburgh EH, Chiswick ML. Foot length-a new and potentially useful measurement in the neonate. Arch Dis Child 1979;54:226-30.

10 Marchant T, Jaribu J, Penfold $S$, et al. Measuring newborn foot length to identify small babies in need of extra care: a cross sectional hospital based study with community follow-up in Tanzania. BMC Public Health 2010;10:624.

11 Marchant T, Penfold S, Mkumbo E, et al. The reliability of a newborn foot length measurement tool used by community volunteers to identify low birth weight or premature babies born at home in southern Tanzania. BMC Public Health 2014; 14:859.

12 Mathur A, Tak SK, Kothari P. 'Foot length'-a newer approach in neonatal anthropometry. J Trop Pediatr 1984;30:333-6.
13 Mullany LC, Darmstadt GL, Khatry SK, et al. Relationship between the surrogate anthropometric measures, foot length and chest circumference and birth weight among newborns of Sarlahi, Nepal. Eur J Clin Nutr 2007;61:40-6.

14 Elizabeth NL, Christopher OG, Patrick K. Determining an anthropometric surrogate measure for identifying low birth weight babies in Uganda: a hospital-based cross sectional study. BMC Pediatr 2013;13:54.

15 Diamond I, McDonald J, Guidotti R. Use of a simple anthropometric measurement to predict birth weight. who Collaborative study of birth weight surrogates. Bull World Health Organ 1993;71:157-63.

16 Arisoy AE, Sarman G. Chest and mid-arm circumferences: identification of low birth weight newborns in turkey. J Trop Pediatr 1995;41:34-7.

17 Hoffman CS, Messer LC, Mendola P, et al. Comparison of gestational age at birth based on last menstrual period and ultrasound during the first trimester. Paediatr Perinat Epidemiol 2008;22:587-96.

18 Lee AC, Panchal P, Folger L, et al. Diagnostic accuracy of neonatal assessment for gestational age determination: a systematic review. Pediatrics 2017;140:e20171423.

19 Marín Gabriel MA, Martín Moreiras J, Lliteras Fleixas G, et al. [Assessment of the new Ballard score to estimate gestational age]. An Pediatr (Barc) 2006;64:140-5.

20 Lynch CD, Zhang J. The research implications of the selection of a gestational age estimation method. Paediatr Perinat Epidemiol 2007;21(Suppl 2):86-96.

21 Grimes DA, Hubacher D, Nanda K, et al. The good clinical practice guideline: a bronze standard for clinical research. Lancet 2005;366:172-4.

22 Ballard JL, Khoury JC, Wedig K, et al. New Ballard score, expanded to include extremely premature infants. J Pediatr 1991;119:417-23.

23 Sanders M, Allen M, Alexander GR, et al. Gestational age assessment in preterm neonates weighing less than 1500 grams. Pediatrics 1991;88:542-6.

24 Dubowitz LM, Dubowitz V, Goldberg C. Clinical assessment of gestational age in the newborn infant. J Pediatr 1970;77:1-10.

25 Goto E. Meta-Analysis: identification of low birthweight by other anthropometric measurements at birth in developing countries. J Epidemiol 2011;21:354-62.

26 Thi HN, Khanh DKT, Thu HLT, et al. Foot length, chest circumference, and mid upper arm circumference are good predictors of low birth weight and prematurity in ethnic minority newborns in Vietnam: a hospital-based observational study. PLoS One 2015; 10:e0142420.

27 Hadush MY, Berhe AH, Medhanyie AA. Foot length, chest and head circumference measurements in detection of low birth weight neonates in Mekelle, Ethiopia: a hospital based cross sectional study. BMC Pediatr 2017;17:111.

28 Lee AC, Mullany LC, Ladhani K, et al. Validity of newborn clinical assessment to determine gestational age in Bangladesh. Pediatrics 2016;138:e20153303.

29 Eregie CO. A new method for maturity determination in newborn infants. J Trop Pediatr 2000;46:140-4. 